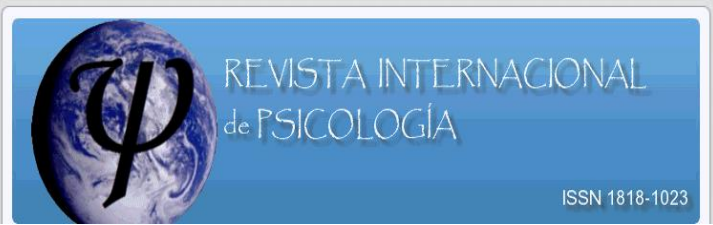

\title{
FACTORES DE RIESGO BIOPSICOSOCIAL QUE INFLUYEN EN EL DESARROLLO DEL TRASTORNO DISOCIAL EN ADOLESCENTES COLOMBIANOS
}

\section{Biopsychosocial risk factors influence in the development of dissocial disorder in colombian adolescents}

\author{
José Alonso Andrade Salazar ${ }^{1}$, Jenny Marcela Barbosa Ñustes ${ }^{2}$, Claudia Ximena Lozada \\ Ramírez $^{3}$
}

\begin{abstract}
RESUMEN
El objetivo de esta investigación es identificar los factores de riesgo biopsicosocial que influyen en el desarrollo del trastorno disocial en adolescentes Colombianos a fin de asociar el inicio de conductas disruptivas con la progresión del trastorno hasta actos delictivos. El trastorno disocial en adolescentes tiene diferentes causas pero una sola consecuencia: la alteridad frecuente y la negación del otro en un escenario de encuentro. En el comportamiento de las personas afectadas tienen influencia factores biológicos, patologías psicológicas y eventos sociofamiliares que refuerzan las conductas agresivas y aumentan la insatisfacción social, la cual determina la formación de conductas delictivas especialmente cuando la persona crece bajo notables desigualdades socioeconómicas, entornos hostiles y déficit en el acceso a oportunidades educativas y laborales.
\end{abstract}

Palabras clave: Trastorno disocial, adolescentes, factores biológicos, factores psicológicos, factores sociales, familia, escuela, grupo de pares, psicología.

\begin{abstract}
The objective of this investigation is to identify the risk factors of psychological influences in the social disorder development in Colombian teenagers to associate the start of disruptive behavior with the risk to progress to potential criminal acts. A social disorder in teenagers can be caused by different things, but there is only one consequence: frequency of otherness and the negating of the other in a potential meeting. The behavior of others that are affected often influences factors such as biological, pathology, psychology and events of partner family relationships that can reinforce aggressive behavior and can lead to social dissatisfaction This can lead to the provoking of criminal acts, especially when the person believes they are under a significant socioeconomic inequality in a hostile environment and that limits the access to education and labor opportunities.

\footnotetext{
${ }^{1}$ Psicólogo clínico. Especialista en Gestión De Proyectos de Desarrollo. Coordinador de investigaciones del programa de psicología de la Universidad de San Buenaventura extensión Ibagué en convenio con la Fundación Universitaria San Martín. Colombia 2012. Email: 911 psicologia @ gmail.com

2 Estudiante del programa de psicología de la Universidad de San Buenaventura extensión Ibagué en convenio con la Fundación Universitaria San Martín. Colombia 2012. Email: marcelita100688@ hotmail.com

${ }^{3}$ Estudiante del programa de psicología de la Universidad de San Buenaventura extensión Ibagué en convenio con la Fundación Universitaria San Martín.Colombia 2012. Email: claudialozadapsicologia@ hotmail.com
} 
Keywords: dissocial disorder, adolescents, biological factors, psychological factors, social factors, family, school, peer group, psychology.

\section{INTRODUCCIÓN}

La agresión entre pares, la violencia de pandillas y la alteridad frecuente al interior de los hogares e instituciones educativas entre otros eventos de agresión, alertan a los sistemas de salud y encaminan las acciones hacia la prevención e intervención oportuna en el campo de la salud mental. Éste trabajo brinda orientación acerca de la etiología biopsicosocial del fenómeno violento en relación al trastorno disocial, tomando en cuenta el modelo de Barkley, Edwards, y Robin (1999) de los cuatro factores de la conducta negativista (practicas de crianza, caracterización del niño o adolescente, características de los padres y factores contextuales) y su relación con el inicio, mantenimiento y comorbilidad de dicho trastorno. En la actualidad la elevada tasa de violencia intraurbana y los cambios en la estructuración psicoafectiva de los hogares Colombianos son en gran medida consecuencia directa de modificaciones históricas importantes en los modos como cada comunidad y familia interpreta y da cuenta de su experiencia individual y colectiva; así, entre las condiciones precipitantes de conflicto social se encuentra el trastorno disocial o alteración del comportamiento caracterizado por conductas antisociales que incrementan la violación de normas sociales, reglas sociofamiliares y el daño a la integridad del otro al no reconocerlo como legítimo otro en la relación de convivencia (Maturana, H. 1995).

El modelo de Barkley et al., (1999), es importante porque entiende los trastornos conductuales como el producto de la interacción de factores sociofamiliares, biológicos y problemas de las funciones ejecutivas, que emergen en niveles de desarrollo evolutivamente inapropiados. En el trastorno disocial los factores sociales y familiares de riesgo tienen interrelación e interdependencia por lo que dichos elementos se instauran en la infancia y presentan una naturaleza relativamente crónica (Barkley, 1990) que se amplía e incrementa en función de condiciones psicosociales específicas. Barkley construye un modelo en el que se incluyen las causas generales y particulares de los trastornos conductuales de manera llana y útil, con el fin de facilitar la intervención terapéutica y la prevención. La idea de integrar en este estudio los elementos biopsicosociales asociados al trastorno disocial, obliga la unificación de las condiciones externas-globales asociadas a los trastornos de la conducta, los factores multietiológicos y los problemas emergentes de las relaciones con la otredad, tomando en cuenta que del modelo de Barkley se incluyen las influencias ambientales e interoceptivas, los factores metacognitivos en cuanto "el saber hacer y cómo hacerlo" que alteran las funciones ejecutivas y median la toma de decisiones, además de la irreductibilidad del modelo a problemas de inhibición conductual, lo que exige el análisis del trastorno disocial a través de la comprensión de conductas encubiertas (de agresión indirecta), privadas (con motivaciones particulares) $\mathrm{y}$ autodirigidas con una clara intencionalidad destructiva (Barkley, 1997).

En Colombia dichos elementos presentan connotaciones especiales que orientan su análisis a condiciones sociales propias de los procesos de anclaje e identificación de adolescentes implicados en problemas con la autoridad, ya que en estos escenarios 
frecuentemente establecen y refuerzan sus relaciones con la otredad (violencia militar, pandillismo, violencia intrafamiliar, entornos hostiles, etc.). De acuerdo con Durán (2006) los adolescentes vinculados a grupos armados (guerrillas, paramilitares, subversión urbana, etc.) son seres humanos que sufren la dureza de vivir en un entorno de violencia que afecta la capacidad que tienen para reaccionar ante el estrés, lo que afecta su salud mental pues, "se ha encontrado que presentan con frecuencia depresión y ansiedad, así como síntomas de estrés postraumático" (p. 190) que influyen en la conformación de trastornos del comportamiento. El modelo de Barkley indica que la amplitud y mantenimiento patológicodisruptivo de estas conductas se encuentra mediado por la confluencia de practicas de crianza disfuncional (ambivalentes, muy laxas o muy estrictas) y por características específicas en niños y adolescentes (agresión, irritabilidad, desprecio por lo social, ausencia de empatía, inconformismo, etc.) que pueden ser vistas como el correlato escenificado de las tipologías comportamentales de los padres o cuidadores con los que estos se identifican en un contexto psicosocial determinado.

En Colombia la etiología del trastorno disocial invita al análisis de factores socioculturales de tipo estructural que devienen del conflicto armado colombiano, la violencia transgeneracional y el antecedente de mas de doce guerras internas que han dejado una huella importante en el sistema de relación de las comunidades. Dichos aspectos son importantes para entender la reciprocidad entre la edad del niño, su nivel de desarrollo cognitivo, el ambiente sociofamiliar y otros aspectos socioculturales relevantes en la dinámica del trastorno disocial (Luciano, 1997; Mash y Graham, 2001; Moreno, 2002, 2005; Díaz y Díaz-Sibaja, 2005; Méndez, Espada, y Orgilés, 2006). Estudios realizados en Colombia (Pineda y Puerta 2001; Rey 2001) demuestran una analogía importante entre la historia de violencia, la prevalencia del Trastorno Disocial y el Trastorno Antisocial de la Personalidad, revelando la prolongación de la violencia infantil a la vida adolescente y adulta, condición directamente proporcional a factores como miseria, pobreza, desintegración familiar (divorcios y núcleos uniparentales), y el vivir en zonas de riesgo con características conflictivas, entre las que se cuenta el fenómeno de la "brutalización" o presencia de un miembro de una pandilla dentro del núcleo familiar (Curie, 2000), especialmente porque la pandilla instaura y refuerza una pedagogía del miedo, pues "muchos llegan a través de él, empujados por la inseguridad y el pánico (en muchos casos huyendo de una familia destruida)" (Perea. C, 2007, p. 6).

El estudio de Pineda y Puerta (2001) acerca del Trastorno de la conducta en adolescentes colombianos, con un muestra aleatoria de 190 adolescentes escolarizados, de 12 a 16 años y de diferentes estratos socioeconómicos de Medellín-Colombia, encontró que las conductas frecuentes en el trastorno de la conducta (TDC) en adolescentes colombianos se relacionan con el hecho de pasar mucho tiempo fuera de la casa en la noche hasta altas horas (sin permiso), ser cruel con los animales y con las personas, entrar violentamente en propiedad privada, en su casa o en el automóvil de otros (irrumpir y violar la intimidad) y usar armas que están a su disposición con el fin de herir a otros, amenazar o causar una impresión de poder y liderazgo entre sus pares. Estudios indican que la prevalencia del trastorno disocial de la conducta (TDC) se sitúa entre un 4 y $10 \%$ (Pineda \& Puerta, 2001), por tanto el Trastorno de la conducta está presente en el 8,4\% de los adolescentes de forma independiente al estrato socioeconómico. Según el estudio nacional en salud mental (MPS, 2004), el Trastorno de conducta tiene una prevalencia del $8.8 \%$ en hombres y $2.7 \%$ en 
mujeres, mientras el Trastorno oposicionista ocurre en un $4.9 \%$ en hombres y $2.2 \%$ en mujeres, con una edad media de inicio de 10 años para ambos trastornos y géneros (MPS, 2004), estos datos indican que en el inicio temprano el género no representa un factor determinante, sino los factores contextuales en los cuales se desarrolla la persona, tomando gran importancia el entorno familiar y comunitario como también, la calidad de las relaciones sociales establecidas desde la infancia, el hecho de asistir a la escuela, la falta de una creencia religiosa y la influencia de modelos inapropiados de identificación externos al núcleo familiar, que en ausencia del padre o de reglas claras en el hogar, se convierten en factores de riesgo que amplían el potencial delictivo en adolescentes con trastorno disocial.

Datos del observatorio nacional de salud mental de Colombia (MPS, 2010), indican que aproximadamente el 6\% de los niños, con edades de 9 a 17 años presentan trastornos de la conducta. El trastorno se presenta con mayor frecuencia en los varones que en las mujeres, en los adolescentes la prevalencia anual del trastorno negativista desafiante es del $2 \%$ con una marcada tendencia en mujeres $(2,5 \%)$ en relación a los hombres $(1,6 \%)$, mientras el trastorno de conducta (disocial) se presentó en un $1,4 \%$ y fue mayor en hombres $(1,9 \%)$ que en mujeres $(0,8 \%)$. La estimación del número de casos esperados para cada uno de los trastornos mentales entre el 2003 y el 2010 indicó un aumento de 3.677 casos para el Trastorno negativista desafiante y 2.494 casos para la conducta disocial (MPS, 2010), con una prevalencia de vida para cualquier trastorno del $16,1 \%$ en adolescentes que han sufrido o sufren uno o más trastornos mentales, siendo mayor esta proporción en mujeres $(17,4 \%)$ que en hombres $(14,8 \%)$. El hecho que en las mujeres el trastorno negativista sea mayor en la infancia es muestra que la movilidad del trastorno en escenarios de escaso control sociofamiliar, se da como efecto de la disfuncionalidad familiar y educativa de la primera infancia sin embargo, cuando dicha condición patológica se sale de control, los síntomas se cronifican hasta convertirse en un trastorno disocial, especialmente en hombres que presentan antecedentes de problemas de salud mental, quizá porque las conductas masculinas se refuerzan más en "lugares socializadores" donde la trasgresión y la fuerza forman parte de los registros de interacción social propios de cada género.

Pineda y Puerta $(2001$; 2001a) consideran que la incidencia del trastorno disocial es elevado en estratos socioeconómicos bajos, lo cual es producto de vivir condiciones de pobreza, escasa educación y tener un mayor número de hijos, lo que conduciría a un menor control de sus conductas por parte de los padres; de acuerdo a ello en estos hogares la existencia de disfunción familiar, divorcios y abandono, actuarían como reforzadores de conductas agresivas que pasan a convertirse en patrones de funcionamiento y comunicación social en niños y adolescentes (Barkley, R. Edwards, G.H y Robin, 1999), como consecuencia la relación entre bajos ingresos, escasa educación y trastornos psicopatológicos, causa una mayor alteración de la funcionalidad intrafamiliar, especialmente cuando se presenta alcoholismo, farmacodependencia y trastornos de personalidad en padres e hijos. Es importante mencionar que uno de los elementos que influye en el crecimiento exponencial de la violencia entre jóvenes Colombianos, es la presencia de un entorno violento que refuerce negativamente la violencia y las agresiones como medio para alcanzar fines determinados, en este sentido la violencia social y política como fenómeno histórico impacta constantemente a población civil que aparece como blanco de ataque de los bandos en disputa. Para Corsi (1999) a nivel macrosocial las distintas formas de violencia social aumentan a un ritmo acelerado y amenazan el proceso de 
integración psicosocial en el que los adolescentes y jóvenes añaden a su vida nuevas capacidades y aptitudes que pueden resultar disfuncionales entre ellos mismos, con el medio social o que atentan contra el orden social establecido.

Ignacio Martin Baró (1984) opina que el proceso de aprendizaje busca estructurar la relación de la persona con su medio, configurando un mundo donde el individuo ocupe un lugar y materialice sus intereses sociales así, los problemas de la crianza y la estructura ideológica del estado (obediencia, adoctrinamiento, sumisión y repetición conductual) son determinantes al momento de entender el trastorno disocial como el resultado de la probabilidad de quiebre de la relación entre la obediencia ideológica ciega, las pautas de crianza que entran en desuso, el instrumentalismo de la educación tradicional y la emergencia de la disfuncionalidad temperamental y caracteriológica propia de la adolescencia (Averasturi \& Knodel, 1996); subsiguientemente el trastorno disocial resulta concomitante a interacción dinámica de fallas en la regulación de estos sistemas, presentando como rasgo principal, un conjunto de conductas de tipo agresivo-desafiante que se estructuran desde la niñez, se refuerzan en la pubertad y se repiten e incrementan en la adolescencia hasta constituirse en un patrón de comportamiento persistente y repetitivo, no reductible a la maldad propia de la infancia o la rebeldía en el adolescente. Acorde con Zuleta (1992) la educación familiar e institucional sobrelleva una crisis visible en el modo como se argumenta y enseña, pues reduce la pedagogía a una trasmisión de conocimientos, por lo que "hay que mostrar en la educación cómo se viola el derecho a pensar, mostrar cómo en todos los campos de la vida moderna se está en contra de los derechos humanos y a estos se les antepone no solo interés y el gobierno, sino también las organizaciones sociales" (p. 56)

\section{GENERALIDADES}

El trastorno disocial conlleva un detrimento en el diario vivir de un sujeto "normal", lo que se referencia en el DSM-IV TR (2002) como un deterioro clínicamente significativo en las áreas: escolar, familiar, social y laboral. En dichos contextos se reproducen conductas que se tornan cada vez más hostiles al formar parte de los correlatos de lenguaje entre pares, lo que apuntala la conducta disfuncional en adolescentes con trastorno disocial pues, la asimilación de ciertas señales y códigos de lenguaje agresivo les permite adherir actitudes agresivas, desafiantes y contestatarias a su personalidad en formación. Generalmente los niños con notables antagonismos afectivos y escasas habilidades sociales, presentan problemas para interiorizar las normas, trabajar en equipo y aceptar señalamientos familiares además, de escasas habilidades para resolver conflictos escolares que a menudo involucran episodios de violencia y actos de vandalismo bajo el efecto de alguna sustancia psicoactiva (SPA), dichas características los llevan a participar de pandillas, grupos delincuenciales, y del Bullying, con el fin de obtener prestigio, respeto y reconocimiento. En el caso del trastorno disocial, las pautas de crianza se asocian al género, el consumo de SPA y a cambios biopsicosociales permanentes que inciden en la decisión de ejercer la delincuencia, cabe resaltar que dichos factores aumentan el riesgo de conductas agresivas con la familia y la comunidad, además de faltas a la autoridad en las que "el consumo de SPA es (...) directamente proporcional al aumento de la conflictividad al interior del hogar, llegando a ser una práctica común entre aquellos individuos adolescentes que delinquen" (Andrade \& Portillo, 2012, p.5). 
El trastorno disocial implica la participación del adolescente en sucesos que incluyen básicamente un conflicto frecuente con la norma sociofamiliar y los símbolos de convivencia implícitos en las relaciones sociales, factor que determina el modo como interpretan lo normativo y la trasgresión a partir de su entorno familiar, comunitario y sociopolítico. En Colombia la carga de enfermedad en adolescentes indica que la mortalidad es baja, siendo las principales causas de mortalidad en el grupo de 10 a 14 años los accidentes, homicidio, ahogamiento, leucemias y suicidio (FIC, 2006), mientras en el grupo de 15 a 19 años prevalecen causas derivadas de traumas y la violencia, los cuales pueden asociarse a la presencia de pautas de comportamiento desafiante y contestatario. Para evaluar el trastorno disocial los tipos de comportamientos pueden ser divididos en cuatro categorías (DSM IV-TR, 2002): a) comportamientos agresivos tales como, inicio de peleas, portar armas, actos crueles contra personas y animales, robo con violencia, violaciones a las normas, y en algunas ocasiones homicidios; b) comportamientos no agresivos con daño a la propiedad privada, sin daño a personas, ocasionar incendios, romper vidrios, dañar automóviles y actividades vandálicas en la escuela; c) fraudes o robos, mentiras, estafas, falsificaciones, romper compromisos y promesas para sacar provecho, hurtos, robo a tiendas, entre otros; d) violaciones a las normas escolares (huidas de clases), leyes y acuerdos familiares. Cabe mencionar que en adultos jóvenes es frecuente el ausentismo laboral, peleas callejeras, una constante sexualización de la conducta e ingesta de alcohol y otras sustancias psicoactivas; por esta razón el trastorno disocial en muchos adolescentes constituye en gran medida una puerta de ingreso a un entorno delictivo que refuerza la conducta de trasgresión como estrategia de desligamiento social y ruptura del orden sociopolítico.

En los niños, niñas y adolescentes con trastorno disocial prima la satisfacción individual antes que el bien común, al respecto Ignacio Martín Baró (1984) afirma que trabajar es primero y fundamentalmente "hacerse a sí mismo" transformando la realidad, encontrándose o enajenándose en el quehacer de relaciones interpersonales e intergrupales; justamente las personas que presentan reiterativamente conductas agresivas, desafiantes o violentas, tienen problemas para integrar la cooperación social-comunitaria como un criterio de realidad que aporte a su desarrollo, afectando la prosocialidad y la sana convivencia; para Zambrano \& Pérez (2004) los factores relacionados con la conducta delictiva juvenil pueden ser clasificados en aspectos que van desde el nivel biológico-individual hasta el nivel sociocultural y la identidad personal y grupal, descartando la idea de que sólo la influencia social es importante, en este tópico Barkley (1997) opina que la gravedad de la desobediencia, la reiteración de la conducta desafiante y las pautas de conducta agresiva conducen a la delincuencia, y se asocian a una naturaleza conflictiva en las relaciones entre padres e hijos (niños, niñas o adolescentes), así aquellos niños con conducta negativista exhiben una pobre calidad del apego hacia sus padres, ya que éstos son poco afectivos y con frecuencia refuerzan positivamente su conducta desviada, lo cual afecta su desarrollo normal. Igualmente los factores de carácter individual y de contexto aumentan la probabilidad que un adolescente desarrolle comportamientos violentos o participe del fenómeno delictivo, lo anterior es lo que Farrington (2002) llama "potencial criminal" o condición en la que se evalúa primordialmente la existencia de diferencias individuales ante la predisposición al comportamiento delictivo.

Para Farrington (2002) el "potencial criminal" depende del transcurso de sucesos que promuevan, impulsen e inhiban los comportamientos agresivos y procesos cognitivos del 
adolescente, por lo que en dicha potencialidad los factores individuales prevalentes son de tipo psicológico y se caracterizan por falta de concentración, escaso autocontrol, hiperactividad, baja tolerancia a la crítica y a la frustración, nivel de inteligencia bajo e impulsividad, destacándose entre las consecuencias resultantes de la presencia de hiperactividad, la relación entre delincuencia y trastornos de la conducta (García \& Armas, 2009). Rutter, Giller, \& Hagell (2000) resaltan una serie de características de vulnerabilidad en adolescentes propensos a infringir la ley y cometer actos delictivos, tales características son: extrema confianza en sí mismo, elevada tendencia a tomar riesgos, abuso de sustancias psicoactivas, hiperactividad, propensión a atribuir la responsabilidad de su comportamiento a fuerzas externas, agresividad a temprana edad, pereza en el ejercicio del pensamiento crítico, dificultad o represión de los sentimientos de culpa, problemas para controlar la ansiedad, disposición a interpretar el entorno como un lugar hostil y sensación de que el mundo es para el propio beneficio y no para el bien común y la prosocialidad. Para Barkley y col (1999) las características temperamentales negativas del niño o adolescente con conducta desafiante lo impulsan a interactuar de forma airada, irritable, explosiva y con pobres mecanismos de control lo que altera sus características cognitivas respecto a la agresión (racionalización y justificación de sus conductas, etc.).

Para el autor el hecho de presentar síntomas de hiperactividad en la adolescencia (pobre control de los impulsos y conducta negativa precoz) y una dinámica familiar conflictiva en la que son frecuentes los enfrentamientos entre padres e hijos, aumenta las probabilidades de responder con emociones negativas ante la presión propia de las relaciones sociofamiliares, dificultando el diagnostico cuando éste patrón de respuesta forma parte de las pautas de crianza familiar, en este aspecto "la conducta disocial junto a otros problemas de conducta suelen mantener un cierto grado de solapamiento a la hora de describir población clínica y no clínica" (García \& Armas, 2009, p. 3). Lo anterior obedece en gran medida a la manipulación de los síntomas por parte del paciente y la ganancia secundaria obtenida de sus acciones. Atkins y Hart (2003) encontraron que en los centros penales el principal factor de predicción de violencia en jóvenes y adultos recluidos es el Trastorno de personalidad antisocial ya que, en ellos emergen problemas de comportamiento a raíz de la alteración de la capacidad para tolerar al otro, resolver los conflictos asertivamente y elaborar Insights, llegando a modificarse tres vertientes conductuales: las relaciones interpersonales, la estabilidad afectiva y la conducta social. Para Barkley las características de los padres juegan un papel básico al momento de evaluar el trastorno ya que la probabilidad de desobediencia, confrontación e irritabilidad en el adolescente puede incrementarse a razón de características similares en padres impulsivos, inexpertos, inmaduros, desatentos, descuidados, deprimidos, hostiles o rechazantes que no cultivan la actividad prosocial, ergo "los padres pueden emplear también la conducta coercitiva con otros miembros de la familia, proporcionando un modelo de conducta a imitar por el niño o adolescente" (Portugal \& Araúxo. 2004, p. 62).

Para muchos adolescentes el hecho de desafiar abiertamente a sus padres u otros adultos otorga cierto nivel de prestigio ante sus hermanos, conocidos y amigos, por este motivo acontecimientos internos y externos a la familia contribuyen al desarrollo de una conducta desafiante que a posteriori eleva el riesgo del acto delictivo (Barkley y col, 1999). Cabe mencionar que estos factores no actúan separadamente de las influencias biológicas, siendo igualmente importante el periodo perinatal y la carga hereditaria. De acuerdo a Portugal y 
Araúxo (2004) los síntomas del trastorno de atención con hiperactividad (TDAH), tales como: hiperactividad, desatención, e impulsividad son propios del temperamento infantil, sin embargo "cuando persisten después en los años escolares, es más probable que creen conflictos de relación entre padres y niños, y posteriormente, entre padres y adolescentes" (p. 61). Un estudio realizado en Argentina por Rojas \& Malpica (2006) reveló que las dificultades durante el parto predecían comportamientos violentos cuando uno de los padres tenía antecedentes de enfermedad mental, igualmente Rhee y Waldman (2002) en estudios de gemelos encontraron que la heredabilidad del trastorno de conducta disocial es del 50\% con un peso en la expresión fenotípica a razón de factores medioambientales no compartidos que alcanza el $39 \%$ en ambos géneros, dicho estudio revela que la personalidad antisocial del adulto (36\%) no guarda relación directa con la heredabilidad del trastorno disocial, evidenciando que las conductas de agresión son mas heredables (60\%-70\%) que el trastorno en sí mismo o su comorbilidad futura. Otras investigaciones proponen que los trastornos del estado del ánimo y la ansiedad de los padres están relacionados con la violencia de los jóvenes (García \& Armas, 2009) en cuyo caso la influencia hereditaria sería innegable pero no determinante del trastorno.

\section{FACTORES BIOLÓGICOS ASOCIADOS AL TRASTORNO DISOCIAL}

Respecto a los factores biológicos asociados al trastorno disocial en adolescentes colombianos se pueden identificar factores parentales y genéticos que forman parte de un conjunto de elementos que interactúan de forma dinámica en un momento específico del desarrollo biopsicosocial del sujeto. Para el Ministerio de la protección social de Colombia (MPS, 2010) la prevalencia del trastorno disocial en la adolescencia es de un 3-9\% frente a un $2 \%$ en la infancia; las evaluaciones neuropsicológicas demuestran que los niños y adolescentes con trastornos de la conducta "parecen tener afectado el lóbulo frontal del cerebro, lo cual interfiere con su capacidad para planificar, evitar los riesgos y aprender de sus experiencias negativas. Se considera que el temperamento de los niños tiene una base genética" (p. 52) por esta razón los niños y niñas presentan un riesgo elevado de desarrollar trastornos del comportamiento en la adolescencia. En Colombia no existen estudios genéticos acerca del trastorno disocial sin embargo, las investigaciones se apoyan en datos de estudios acerca de la influencia mutua de una serie de características a nivel neuronal tales como, hormonas, neurotransmisores, neuropéptidos, actividad cortical y toxinas (Scarpa \& Raine, 2000; Brennan, 1998; Farrington, 2004), dichas condiciones emergen por la aparición de la conducta violenta a razón de una excitabilidad importante del sistema límbico en un proceso de disrregulación de la actividad de la corteza prefrontal (Anckarsater, H. 2006), proceso que está asociado a la relación entre el incremento de los niveles plasmáticos de testosterona y la acentuación de la concentración de norepinefrina, lo que acrecienta la probabilidad de ejercer comportamiento antisocial en varones (Olweus, Mattsson, Schalling y Löw, 1980).

En estas investigaciones se encontró que el aumento de los niveles de testosterona es uno de los mediadores biológicos determinantes del acto violento (Raine, Lenz, Bihrle, LaCasse \& Colletti, 2000). Un estudio longitudinal descubrió que los jóvenes de 13 años clasificados como "líderes bravucones" presentaban concentraciones más altas de testosterona que sus compañeros, siendo sus niveles generales de andrógenos más bajos que los de los sujetos no agresivos, el estudio se apoyó en la evidencia de que el rechazo social disminuye el nivel de 
testosterona mientras un deseo de popularidad mayor podría incrementarla. A pesar de esto los resultados muestran prevalencias a los 15 y 16 años de edad, espacio donde el nivel de testosterona de los sujetos agresivos era mayor en comparación con el de los adolescentes no-agresivos (Tremblay, Schall, Boulerice y Perusse, 1997). Asimismo junto a la testosterona el sistema serotoninergico es considerado un aspecto central en la regulación de la conducta agresiva de tipo impulsivo (Spoont, 1992), al igual que determinadas toxinas y nutrientes, cuya actividad neurobioquímica se han relacionado con las conductas antisociales, principalmente en hijos de padres alcohólicos cuyo riesgo es sustancialmente mayor porque pueden desarrollar una conducta antisocial además de otros tipos de patologías (Steinhausen, 2003). Otras investigaciones a nivel familiar con gemelos, indican que los antecedentes de consumo de alcohol en los padres está asociada a mayores tasas de TDAH (Knopik, Heath, Jacob, Slutske, Bucholz, Madden, 2006), trastornos de conducta, y al trastorno oposicionista desafiante (Lahey, Piacentini, McBurnett, Stone, Hartdagen \& Hynd, 1988; Malone, Iacono \& McGue, 2002).

Igualmente se ha descubierto que existe un vinculo cercano entre el trastorno de la conducta, el comportamiento antisocial a futuro y el consumo (abuso y dependencia) de sustancias psicoactivas (Herndon \& Iacono, 2005; Marmorstein, Iacono \& McGue, 2009). Respecto a las anomalías cromosómicas, a mediados de los años 60`s el estudio de Jacobs, Brunton, Melville, Brittain y McClermont (1965) en delincuentes privados de la libertad, halló una presencia importante de la anomalía cromosómica XYY (Muñoz, J. 2004), dichos hallazgos generaron la tendencia a creer que los psicópatas eran personas con dones especiales en cuanto masculinidad (más fuerza, más inteligencia, mayor control de sus conductas y habilidades de planificación superiores), por lo que su principal característica fue su extremada violencia e impulsividad dotada de una inteligencia superior mal aprovechada. Aunque los comportamientos delictivos sean claramente numerosos en los individuos con este patrón cromosómico (XYY) en comparación con los XY, se ha encontrado que los delitos son relativamente triviales y no trascienden hasta el limite del asesinato o el atentado grave al bien publico y privado (Witkin, HA. Goodenough, DR. 1977). Igualmente Walzer, Bashir y Silbert (1990) descubrieron que los individuos XYY tienen un sumario de delincuencia superior (pero no exageradamente diferencial) al de los individuos XXY, por ello aunque dicho índice es prácticamente igual que el de la población general, no puede atribuirse el delito a causas específicamente congénitas, aprendidas, como fruto exclusivo de los conflictos sociales o en relación con discapacidades estructurales (deficiencias, las limitaciones de la actividad y las restricciones de la participación).

De acuerdo con Rutter y col (2000) la presencia de la condición cromosómica XYY no es la causante de delincuencia directamente, aunque adjunta a otros factores, incrementaría la probabilidad de desarrollar conductas antisociales. El estudio clásico de Robins (1966) situaba el comportamiento criminal del padre como uno de los mejores predictores de la conducta antisocial del hijo, sin embargo en los últimos años se han acumulado evidencias a favor una heredabilidad de las características biológicas moduladoras de la conducta delictiva puesto que, la influencia biológica en la conducta agresiva y antisocial del individuo resulta importante para identificar la magnitud de la respuesta violenta ante eventos en que la persona es provocada o desafiada por otros (Geen, 1998). Al respecto los investigadores Dionea, Tremblay, Boivin, Laplante, y Pérusse (2003) llevaron a cabo un estudio con gemelos monocigóticos (idénticos) y con gemelos dicigóticos (fraternales) de 19 
meses de nacidos, encontrando una correlación mayor en las medidas de agresión física en gemelos idénticos, que en gemelos fraternales, dichos resultados demuestran la importancia de la herencia, sin dejar de lado la relación inseparable del contexto de desarrollo psicosocial, mismo que actuaría como disparador de la agresión o en su defecto como regulador de la conducta agresiva, aun cuando la carga hereditaria sea elevada. Es importante mencionar que respecto al origen del trastorno disocial los síntomas emergentes provienen de la constante disrregulación de la conducta en escenarios normativos, condición que puede ser analizada como parte de una etiología biológica determinada por la herencia, lo que no deja exento otros factores biológicos de base hereditaria y psicosociocultural (cultura y tendencias primitivas) que a nivel de especie presentan una elevada incidencia en las conductas de trasgresión y tenacidad de las relaciones sociales (Marina \& López, 1999; Valdez, Díaz \& Pérez, 2005).

Éstas conductas son propias de un entorno aversivo que inhibe el desarrollo psicosocial del adolescente en el que el mantenimiento, cronicidad y agudización de la intensidad de los síntomas propios del trastorno disocial, se da en función de la persistencia de patrones de comportamiento disruptivo en niños o adolescentes cuya característica principal, es la violación frecuente y planificada de los derechos de otros y de las normas sociales de convivencia. Según lo expuesto el trastorno disocial presenta antecedentes importantes derivados del trastorno negativista desafiante y la hiperactividad a nivel comórbido (Barkley, 1998; Martínez M., Henao G., Gómez L, 2009), lo que alerta sobre la probabilidad de estructuración de dicho trastorno, en adolescentes colombianos expuestos a diversas vulnerabilidades sociofamiliares, con una carga hereditaria de TDAH (Tannock R, 1998, Sklar P, 2005; Khan \& Faraone, 2005) y problemas conductuales en la escuela (Martínez M., Henao G., Gómez L, 2009), por ello el trastorno disocial presenta antecedentes importantes resultantes del trastorno negativista desafiante y la hiperactividad a nivel comórbido (Martínez M., Henao G., Gómez L, 2009) ocasionando problemas sustanciales de adaptación social, indisciplina, e incluso conductas de trasgresión mayor como delitos tipificados por la ley como punitivos o correccionales.

\section{FACTORES PSICOLÓGICOS}

En Colombia el 19,6\% de personas son adolescentes (DANE, 2005) que se desarrollan en entornos de características agresivas a razón de los efectos directos (desplazamientos, exclusión social, etc) e indirectos (temor, desconfianza, etc.) del conflicto armado, la delincuencia común y el terrorismo generalizado (estado de guerra interna), por lo que en gran medida la fragilidad mental propia de su edad, sumada a condiciones de inestabilidad familiar y sociopolítica los ubica como una población de alto riesgo frente a la posibilidad de experimentar conductas violentas (como victimas o victimarios), consumo de sustancias psicoactivas y actos delictivos entre otros; estas condiciones los tornan cada vez más proclives a experiencias de crisis, conflictos sociofamiliares, y contradicciones (Monroy A. 1995) que promueven el inicio de conductas disruptivas propias de la etiología del trastorno disocial. Según la OMS (2005) el 13\% de toda la carga de morbilidad en salud mental en el mundo tiene su base en los trastornos neuropsiquiátricos, por ello los factores psicológicos son significativos en el desarrollo del ser humano y tienen gran importancia en el inicio, estructuración y mantenimiento de patologías mentales como el trastorno disocial, lo cual 
invita a una revisión de los problemas conductuales durante la niñez y la adolescencia tales como, el trastorno de déficit de atención con hiperactividad, el trastorno oposicionista "negativista-desafiante" (Hart, E. y col, 1995) y el trastorno de la conducta (Loeber \& Hay, 1997) que son comórbidos y actúan como elementos diferenciales en el diagnóstico. Para Pineda \& Puerta (2001) entre las características psicológicas asociadas al mantenimiento del trastorno disocial se encuentran el hecho de dar continuidad al hecho de permanecer fuera de la casa en la noche (10.5\%), ser cruel con los animales (8.4\%) y con las personas (7.4\%), entrar violentamente en la casa o en el carro de otros $(7.3 \%)$, y el uso de armas con la finalidad de herir a otras personas $(6.9 \%)$.

Cabe mencionar que la comorbilidad per se no es suficiente para explicar la dinámica de los trastornos de la conducta, por ello la aplicación del modelo multietiológico de Barkley (1990) permite la elaboración de un tratamiento ajustado a las pautas de crianza, la características del niño, del adolescente y de sus padres, en relación a un contexto específico, lo que conlleva el análisis de rasgos de personalidad compartidos entre jóvenes infractores y adolescentes con trastorno disocial tales como, impulsividad, dificultad para postergar la gratificación, autoconcepto disminuido, falta de habilidades sociales, bajo nivel de empatía y poca capacidad para sentir culpa (Blackburn, 2000). La estabilidad psicológica de los adolescentes fluctúa cuando se enfrentan a situaciones críticas que exigen de ellos autocontrol y empatía social así, a nivel de actitudes es frecuente la desaprobación verbal, desconfianza a lo nuevo y defensas psicológicas que implican agresividad ante un entorno considerado poco gratificante, de escasa confianza y excluyente; para Barkley y col (1999) un aspecto adicional es la contribución de los padres u otras figuras de poder con características psicológicas disfuncionales, lo que aumenta la probabilidad de generar un clima familiar con predisposición al negativismo.

Frecuentemente las personas con trastorno disocial presentan comportamientos hipercinéticos reiterativos que incluyen actos de impulsividad, agresión y baja tolerancia a la frustración, por ello la presencia de hiperactividad en los adolescentes con trastorno disocial guarda relación con la posibilidad de ejercer la delincuencia de forma temprana o de reincidir en el delito una vez iniciada la vida adulta (Rutter y Guiller, 1988; Farrington.

1995; Orjales, V. 2003). Estudios complementarios de niños con hiperactividad y falta de atención en la niñez temprana o media, indican que su diagnóstico a edades tempranas puede resultar un excelente predictor de conductas disfuncionales posteriores, constituyéndose en un elemento predictivo y preventivo del desarrollo de conductas hostiles y antisociales en la adolescencia (Campbell, 1999; Taylor, Chadwick, Heptinstall y Canckaerts, 1996). En cuanto a los desórdenes internos del control de los impulsos y del estado de ánimo, se incluyen síntomas como la ansiedad flotante y la depresión emergente, puesto que muchos individuos que presentan conductas antisociales manifiestan trastornos del humor (Patterson, G. Reid, J. Dishion, T. 1992) que persisten desde etapas tempranas de desarrollo y se incrementan en la adolescencia y la juventud. De acuerdo con Sanabria y Uribe (2007) la delincuencia juvenil en Colombia comienza desde etapas tempranas (10 años) lo que enuncia un mal pronostico respecto a conductas delictivas en la adolescencia, así las conductas agresivas y de transgresión se tornan cada vez más antisociales, llegando a progresar hasta comportamientos delictivos mayores como parte de su repertorio conductual. 
Según Acero, Escobar y Castellanos (2007) al analizar las características de los adolescentes colombianos que cometen homicidio en masa (tres o más víctimas) es visible el abuso de alcohol y de otras sustancias psicoactivas, algunos de ellos llegan a ser solitarios y agresivos, y presentan síntomas depresivos conjuntamente con antecedentes de enfermedades psiquiátricas (hasta en un 23\%), estos adolescentes regularmente han tenido algún factor desencadenante y se pueden agrupar en tres grupos definidos como: aniquiladores familiares, vengadores del salón de clases y criminales oportunistas (Meloy, Hempel, Mohandie, Shiva \& Gray, 2001). Al respecto estudios demuestran que los individuos con conductas antisociales presentan trastornos emocionales, entre los que aparecería la depresión y un autoconcepto disminuido (Achenbach. T, 1991; Caron \& Rutter, 2000), condición que induciría la búsqueda de respeto y estatus social a través del temor y la sumisión provocada en la victima (Litrownik, Newton, Hunter, English \& Everson, 2003). Otros comportamientos van desde la conducta violenta como identidad creada, hasta la búsqueda de obediencia por parte de sus seguidores y una elevada rigidez en el manejo de sus ideas. Entre los factores psicológicos asociados al trastorno se encuentran igualmente, la dificultad para sentir de empatía por el otro, ausencia de remordimiento por el dolor ajeno, autoestima distorsionada (grandiosidad, megalomanía o embotamiento afectivo y abulia), búsqueda constante de sensaciones, deshumanización de la victima, distorsión de las consecuencias de sus acciones, irresponsabilidad, extroversión, hedonismo, impulsividad, resistencia a conformar y fortalecer un locus de control externo, manipulación, auto justificación constante, necesidad de control y poder, celotipia, paranoia, y motivación por experimentar la rivalidad para reforzar su egocentrismo (Wiggins, J. Pincus, A. 1989; Tellegen, A. 1993; Caballo, V. Simón, M. 2005).

\section{FACTORES SOCIALES}

El trastorno disocial tiene gran influencia en el comportamiento antisocial de adolescentes y jóvenes así, sus consecuencias suelen ser tan nocivas que pueden desembocar en actos delincuenciales tales como la violencia criminal y la delincuencia organizada, las cuales son muy visibles en la sociedad actual (Redondo, S., Sánchez-Meca, J. y Garrido. V, 1999). Según Sanabria y Uribe (2007) en Colombia los jóvenes infractores (de ambos géneros) se caracterizan por actos delictivos como el robo, tráfico, y porte o fabricación de estupefacientes (especialmente en mujeres) y "la fabricación, tráfico y porte de armas de fuego o municiones en los hombres" (p. 111), mostrando una tendencia marcada en cuanto factores etiológicos que provienen de variables biológicas y evolutivas, al tiempo que una relación indisoluble con el contexto sociofamiliar y los escenarios pedagógicos donde el adolescente se desarrolla (Barkley y col, 1999). El acto delictivo en adolescentes colombianos a menudo está mediado por el consumo de sustancias psicoactivas, de acuerdo al Ministerio de la protección social (2004) el 65\% los adolescentes escolares entre 12 y 17 años consume alcohol, tabaco $(35,8 \%)$, sustancias asociadas a trasgresiones a las normas familiares y sociales. Para Estanislao Zuleta (1980) la eficacia de la educación actual cae en un error al preparar futuros profesionales, los cuales se miden por medio de habilidades para desarrollar múltiples tareas, actividades, funciones $\mathrm{u}$ oficios dentro de un sistema productivo, dicha tendencia es excluyente al reducir el éxito y el prestigio a un cumulo de habilidades "mecanizadas", conocimientos y posibilidades lejanas de acceso al saber, por lo que la agresión puede surgir de las diferencias en dichas habilidades y vivencias "producto 
probablemente de experiencias violentas, de la imposibilidad de lograr acceso a bienes y servicios en condiciones de legalidad, de ofertas de remuneración que equivalen a años de trabajo y generalización de la nueva practica" (p. 187).

En gran medida el inicio de los factores sociales asociados al trastorno disocial en adolescentes colombianos guarda una relación directamente proporcional con las manifestaciones de la violencia sociopolítica en los espacios familiares, puesto que el estrés de las necesidades biopsicosociales (tradicionales y emergentes) y las marcadas diferencias de clase establecidas a través de la condición de estrato (clasificación socioeconómica de la población) tiene un efecto negativo sobre la construcción de la identidad en el adolescente, tornándola indecisa, contestataria, inestable e inconforme, y aunque dichas actitudes son propias del desarrollo adolescente (Averasturi \& Knodel, 1996), cuando la familia presenta características violentas, la tendencia a la alteridad natural del adolescente se incrementa a tal punto que provoca un deseo constante de compensación y ruptura del ordenamiento adulto a través de una motilidad (digital y analógica) agresiva, que en casos extremos se ve apuntalada por la presión de un grupo de pares que motiva y aprueba el ejercicio de las conductas violentas y delictivas. Para el estudio del trastorno disocial es importante tomar en cuenta la elevada influencia de factores sociofamiliares, campo en el que Henao (2005) describe dos modalidades de la violencia cotidiana: a) la que es fruto de la actividad del crimen organizado o "violencia común" y, b) la violencia domestica o intrafamiliar (VIF) en la que se incluye la violencia sexual, tomando en cuenta que en el caso de problemas de pautas de crianza, los adolescentes victimas de actos de agresión al interior de su hogar suelen confrontar mucho más a sus padres, lo que según Barkley y col (1999) tiene como resultado agresiones, autoagresiones, destrucción de la propiedad y abusos físicos por parte del padre que ingresa en la dinámica agresiva que domina la relación con el hijo. En los adolescentes con trastorno disocial la familia tiene gran influencia en el inicio y el mantenimiento de los síntomas ya que, frecuentemente los comportamientos violentos tienen su origen en la niñez en el seno de las familias. Para Barkley en estos adolescentes el proceso de socialización se transversaliza por factores de riesgo asociados a la psicopatología de los padres, y un pobre funcionamiento familiar y matrimonial que fomenta la modificación de los modos de actuar de niños y adolescentes cuando refuerza y aprueba el desafío, la irritabilidad y las agresiones.

Por ello cuando los patrones de comportamiento antisocial no se modifican positivamente, se convierten en refuerzos de la conducta disfuncional, lo cual incrementa el peligro de que niños, niñas y adolescentes se tornen agresivos e incurran en delitos, pues "cerca de la mitad de cualquier muestra de niños antisociales continúa siendo antisocial en la adolescencia, y cerca de la mitad de cualquier muestra de adolescentes antisociales continúa siendo antisocial en la adultez" (Farrington, 1994, p. 553; citado por Torrente \& Kanayet, F. 2005), condición que brinda evidencia de la trascendencia epidemiológica del trastorno. A nivel de Colombia las variables de personalidad, familia, núcleo de pares y ambiente están directamente asociadas a la violencia en los adolescentes (Brook, D, Brook, J, Rosen, De la Rosa, Montoya \& Whiteman, 2003), así en el aspecto de la personalidad los adolescentes de comportamiento violento son aquellos que consumen sustancias psicoactivas, y también quienes resultan muy tolerantes con las trasgresiones a la norma; en el aspecto familiar se identificó que el consumo alguna sustancia psicoactiva por parte de los padres y hermanos es un predictor importante de la conducta violenta, asimismo en el tópico de los amigos, la 
influencia de pares consumidores de drogas, disociales y con antecedentes delictivos predice también el desarrollo de conductas hostiles en los jóvenes (Brook et al., 2003).

A nivel de comorbilidad los factores individuales tales como, problemas de tipo cognitivo y rasgos de personalidad agresiva-impulsiva, se unifican a complejos procesos de socialización y factores culturales donde la violencia es constante y propicia la emergencia de problemas de comportamiento agresivo en los niños y niñas (Klevens, 2000). En el ámbito social factores predisponentes como la inequidad social y la pobreza actúan como reforzadores de trastornos comórbidos al trastorno disocial, en escenarios de relación que implican el convivir en un nivel socioeconómico bajo, presentar estilos y prácticas de crianza disfuncional que se heredan y reproducen de forma generacional, como también ser testigo de agresiones entre los padres y verse expuesto a constantes actos de violencia familiar (estrés agudo) y social. Ergo el hecho de crecer en familias conflictivas y participar de grupos de pares con conductas delictivas aumenta el riesgo de desarrollar un trastorno disocial, especialmente cuando dichos elementos se asocian al maltrato físico vivido durante la primera infancia (Llorente, Chaux, \& Salas, 2005), y la observación de la violencia en el ámbito comunitario a nivel urbano y rural (Kuther \& Wallace, 2003). En dicho aspecto la violencia sociopolítica, la saturación de información ambivalente, el aumento de las necesidades de consumo, las nuevas formas de ejercer la violencia, la insatisfacción de necesidades básicas, las conductas adictivas y un estado de incertidumbre ante el futuro, conforman un clima de desarrollo psicosocial en el que "la saturación social (...) proporciona una multiplicidad de lenguajes del yo incoherentes y desvinculados entre si" (Gergen, K. J. 2006, p. 26) que afectan negativamente la interacción familiar.

De acuerdo a Erikson (1959) la sociedad y la cultura influyen de manera importante en el desarrollo de la personalidad, por lo que una atención negligente por parte de los padres en los primeros años puede llevar a que el niño desarrolle un sentimiento de desconfianza e intérprete los estímulos afectivos como hostiles, reaccionando de manera impulsiva y muchas veces agresiva. Piaget (1969) considera la agresión, ligada a la influencia de factores sociales, la interacción con el medio y a elementos educativos y culturales que varían de una sociedad a otra (Charles \& Scheier, 1997), por ello la agresión y la violencia emergen en gran medida por el desequilibrio factorial es decir, por fallas constantes del sentido de autorregulación sociofamiliar, condición que dificulta en el adolescente, el paso de un estado de menor homeostasis (excitación violenta) a uno de mayor equilibrio (autocontrol). Lo anterior indica que tanto la familia como la comunidad puede tener un efecto potencialmente destructivo y determinante de las conductas violentas en adolescentes con trastorno disocial, principalmente cuando se asocian a eventos de violencia intrafamiliar y al consumo de sustancias como el alcohol (Margolin \& Gordis, 2000). Cabe mencionar que dicho consumo por parte de los padres y la dependencia a diversas drogas, elevan el riesgo de que el adolescente presente una amplia gama de tendencias psicopatológicas (Marmorstein et al., 2009); de este modo otras consecuencias del trastorno se asocian a peleas constantes por territorios (Llorente et al, 2005), grupos de pares inapropiados que se consolidan en guetos desde temprana edad (Schwartz \& Proctor, 2000) y entornos biopsicosocialmente inseguros. 


\section{DISCUSIÓN}

Es necesario aclarar que si bien el desarrollo de conductas delincuenciales guarda una relación importante con el trastorno disocial, dicha unión no constituye una condición sine qua non, situación análoga a la disfuncionalidad familiar, la negligencia o la enfermedad mental, pues no todos los delincuentes son enfermos mentales y no todos los adolescentes con trastorno disocial cometen delitos tipificados en el código de infancia y adolescencia, por lo que el diagnóstico clínico no es garantía de la ocurrencia del delito si no se tiene una relación de causalidad inherente al acto (Sánchez, G, 2000). En Colombia la presencia e incremento de la delincuencia juvenil no es exclusiva de una región, edad, trastorno mental o grupo étnico, ergo dicho problema alerta sobre las condiciones de inclusión, prevención y contención de los organismos reguladores del estado y la sociedad, en cuyo caso la competencia de las instituciones debe apuntar a un reordenamiento social y la exigencia constante de los deberes y derechos de los niños y adolescentes a fin de proteger la vida social-comunitaria como garantía del ejercicio y goce efectivo de los derechos humanos. El trastorno disocial como cuadro psicopatológico puede ser un descriptor cercano al comportamiento delincuencial futuro por lo que la conducta delictiva de los adolescentes constituye un problema de toda la comunidad, factor que obliga su resolución en dichos escenarios (Rodriguez, M. 2008).

Para que un adolescente tenga la categoría de criminal la falta cometida debe estar contemplada en el código de infancia y adolescencia y sus efectos deben ser tan nocivos que atenten contra la integralidad de las personas, comunidades y sus bienes, por ello "se debe entender por criminalidad juvenil la ejecución de conductas que de ser realizadas por adultos darían lugar a la imposición de una pena" (Rodriguez, M. 2008, p. 357), condición que conlleva a un análisis de la situación psicoafectiva de la persona que trasgrede las normas. Lo anterior evidencia que la trasgresión presenta unos estándares en cierta medida "admisibles" pues la sociedad la tolera y castiga levemente, por ello el hecho de desafiar los elementos reguladores de la conducta prosocial no se constituye en un elemento probatorio suficiente para pensar en la delincuencia como efecto de trastornos psicopatológicos inherentes o asociados (Garrido \& López, 2006). En el trastorno disocial la familia puede llegar a constituirse en reforzante de las conductas disruptivas de adolescentes que por la inestabilidad emocional propia de la etapa de desarrollo incurren en actos delincuenciales por probar que pueden desafiar a sus padres, participar de grupos en los que obtienen prestigio o por comprobar que no pueden ser desafiados abiertamente; por esta razón el trastorno disocial se torna multidimensional en sus consecuencias y multietiológico en cuanto sus causas ya que, "no sólo la familia se encuentra en este lugar de responsabilidad

social, hay otros ámbitos de construcciones socializantes y de sociabilidades, como la escuela, los grupos de pares, los medios, las relaciones de vecindad y en general las relaciones sociales y el entorno" (Palacio, V. 2011, p. 18).

Cebe mencionar que los factores de riesgo involucrados en la emergencia del trastorno disocial no surgen en ausencia de factores protectores, sino en función de su mal funcionamiento y escasa operatividad en un contexto de reproducción de patrones de crianza disfuncional, como también por la escasa, nula o inapropiada resolución de conflictos en momentos de crisis. En relación a la etiología posible del trastorno, las complicaciones sociales y psicológicas sumadas a aspectos bilógicos derivados de problemas perinatales 
durante el parto, en gran medida pueden predisponer la emergencia de comportamientos violentos, primordialmente cuando uno o ambos padres tiene antecedentes de enfermedad mental. Consumo de SPA o actividad delictiva (Barkley, 1999) y aunque dicho hallazgo no es una condición sine qua non permite establecer una directriz para el actuar preventivo y el manejo de pautas de crianza afectivas con los niños, niñas y adolescentes que cumplen los parámetros de un trastorno de la conducta. Análogamente estudios proponen que los trastornos del estado del ánimo en los padres y los problemas de ansiedad están interrelacionados con la instauración de conductas desadaptativas, un ejemplo de ello es la presencia de una discapacidad de aprendizaje, anomalías físicas menores que generan sentimientos de inferioridad y culpa (Acero et al., 2007), la hiperactividad con déficit de atención (Ferrando-Lucas, MT, 2006), traumatismo craneoencefálico, sufrimiento fetal, además del desarrollo deficiente de la habilidad motora, complicaciones biológicas generalizadas y una carga genética con disfuncionalidades cromosómicas (Bornovalova et al., 2010).

Igualmente es posible afirmar que si bien muchos factores social-comunitarios e individuales de tipo psicológico definen las características de personalidad antisocial llegando a ser relevantes en la prevención, diagnostico, tratamiento y pronostico del mismo, es la conjunción de lo biológico, psicológico y social, lo que determina las relaciones de simbolización presentes en la estructura psicológica de las personas afectadas por el trastorno, en consecuencia una correcta aproximación al estudio de la patología debe incluir por defecto la correlación dinámica de estos tres elementos, condición que por una parte limita la especificidad etiopatológica al ampliar la validez de los criterios patognomónicos, al tiempo que permite una conceptualización ajustada al devenir de los acontecimientos sociales y las nuevas demandas de estimulación del sistema nervioso central en los adolescentes actuales. En dicho aspecto es invariable la idea de que la delincuencia se concentra marcadamente en algunas familias y se transmite en mayor grado de generación en generación a través del proceso de modelado pues, tanto la observación de eventos violentos, como el hecho de ser victima de maltratos en la infancia, incrementa la probabilidad de desarrollar problemas de comportamiento antisocial (Litrownik et al., 2003), lo cual se relaciona con el tipo de apoyo, protección y comprensión recibida por los padres en momentos de crisis familiar, además del riesgo de ser victima de actos de violencia en la comunidad en la que se convive (Rosario, Salzinger, Feldman y Ng-Mak, 2003).

En cuanto a la atribución de los factores de riesgo de tipo social, es necesario resaltar la influencia del sistema familiar en el progreso de conductas delictivas, puesto que quienes son más proclives al trastorno presentan familias monoparentales, pobreza o miseria, familia con más de cuatro hijos, involucramiento familiar en conductas delictivas, abuso y negligencia (Robins, 1981); dichos elementos per se constituyen factores de riesgo importantes pero no representan la totalidad de los problemas sociales asociados al trastorno disocial en adolescentes, aunque pueden constituirse en elementos que refuercen el ingreso a la delincuencia bajo escenarios de relación donde el crimen, la violencia o la tendencia a trasgredir las normas por mero placer constituyen un puente comunicacional que fortalece la relación con otros considerados como pares. La importancia de la influencia del grupo de pares indica que los jóvenes y adolescentes con conductas delictivas procuran tener amigos implicados en actividades ilícitas pues estos comportamientos son aprendidos y reforzados frecuentemente en su contexto social (Schwartz y Proctor, 2000), así, otros factores de 
riesgo social orientan las investigaciones hacia la influencia de las desventajas socioeconómicas, los imaginarios sociales respecto a las clases sociales, la cultura de pares frente a la idea de poder y dominio territorial, la necesidad de estatus y reconocimiento a través del delito y el desempleo juvenil entre otros, en general las conductas desadaptadas de los adolescentes con trastorno disocial que delinquen, se deben más a factores socio ambientales que se sistematizan y reproducen en diversos escenarios de relación, que a alteraciones genéticas propias de la actividad de los neurotransmisores (Hudziak, 2003; Ferrando, L., 2006)

Respecto al tema del tratamiento de los trastornos de la conducta es importante mencionar que los tratamientos de los adolescentes con trastorno disocial suelen ser limitados, pues no traspasan la línea del asistencialismo en los lugares donde son detenidos, como consecuencia la falta de una cultura de la salud mental, el alivio sintomático o paliativo y el escaso análisis interdisciplinario, sumado al desinterés personal y familiar respecto a su mejoría, dificultan la reproducción y reforzamiento de aprendizajes positivos, favoreciendo la reincidencia en la conducta violenta y delictiva, al tiempo que una posible comorbilidad de nuevos trastornos en adolescentes con antecedentes criminales, mismos que pueden desarrollar un trastorno explosivo intermitente o el trastorno antisocial de la personalidad. Sin embargo aunque esta información parece desalentadora, contrariamente a lo expuesto existen pruebas de que algunos tratamientos logran un efecto beneficioso sobre los delincuentes juveniles (Simon 1998); uno de ellos es la terapia multisistémica (Borduin, 1999; Henggelerl y col, 1998) que basa su intervención en la familia, considerada como el primer escenario de identificación y tratamiento de los factores que favorecen la emergencia y el mantenimiento de las conductas delictivas y violentas, esencialmente de aquellos adolescentes que se ven sometidos a tratamiento psicológico por problemas de conducta (Anderson \& Bushman, 2002).

\section{CONCLUSIONES}

La agresión y la violencia en todas sus manifestaciones son consecuentes a etapas del conflicto social innegociables por la vía del dialogo, que pueden determinar la emergencia o el reforzamiento de trastornos de la conducta, pues antes de la inmediatez de los impulsos y la elección de agredir a otro, existe una serie de condiciones biopsicosociales que estipulan la intensidad de dichas acciones; por ello es inevitable que los miembros de la sociedad interactúen diariamente en escenarios donde se ven avocados a reaccionar en función de situaciones específicas ya que, el comportamiento del adolescente con trastorno disocial suele ser de tipo contestatario o conllevar en cierta medida otras reacciones que se encuentran adscritas al repertorio de reacciones aprendidas en su proceso de socialización. Grosso modo el trastorno disocial se presenta como un trastorno multifactorial y policonsecuente que implica un análisis histórico, genético y social de sus derivaciones psicosociales asociadas, en consecuencia dicha motilidad no es la causa reina de los comportamientos agresivos sino, en muchos sentidos la consecuencia dinámica de una serie de eventos que confluyen en escenarios de relación donde los niños, niñas y adolescentes se ven abocados a establecer reacciones antes que deducciones de los sucesos.

Los modelos biopsicosociales tienen una característica integrativa y dinámica, en este sentido esta revisión investigativa, permite un acercamiento a la explicación de los factores 
biopsicosociales vinculados al trastorno disocial en adoelscentes Colombianos, tomando en cuenta la interrelación e interdependencia de los factores de riesgo, y la progresión mórbida de los síntomas psicopatológicos en los diversos escenarios de desarrollo e interacción social. El trastorno disocial puede ser analizado en cuanto etiología, mantenimiento y comorbilidad de síntomas y trastornos, sin embargo una visión complementaria del análisis debe incluir las condiciones humanas y socio-históricas que pueden tornar agresiva a una persona o comunidad respecto a otra o respecto a la institucionalidad, como también las implicaciones sociales, culturales, económicas, políticas y religiosas vinculadas a los actos violentos y la delincuencia en adolescentes. Este tipo de modelos privilegian la retroalimentación constante entre elementos antes que la hegemonía de algunos síntomas que por sí solos no abarcan la totalidad explicativa de las conductas de trasgresión y agresividad con otros, teniendo como base la idea de que sólo la interacción entre elementos biopsicosociales propios de los sujetos analizados, sumado a una dinámica sinérgica de tipo relacional y sistémica, puede dar cuenta de la especificidad de la conducta disocial en un colectivo determinado de personas. Ergo lo biopsicosocial se instaura como posibilidad explicativa dialéctica, donde los factores biológicos tienen gran relevancia al momento de encontrar razones etiopatológicas de base orgánica, pero no son suficientes para explicar la transición del trastorno a estadios mayores de conducta disruptiva o criminal.

Es importante mencionar que los programas de intervención respecto a la criminalidad y en especial aquellos que tienen evidencia de un trastorno de la conducta como base psicopatológica, al tiempo que la disfunción familiar y social de manera concomitante, deben servir de clave para la construcción de una línea estratégica de intervención psicosocial que sirva como marco de referencia pedagógica para emprender acciones de prevención, sostén emocional y apoyo familiar ante las conductas violentas, así el mantenimiento y reincidencia en estas conductas podrá disminuir cuando se tome como eje primordial a la familia, siendo ésta la fuente promotora de habilidades de control emocional y de resolución creativa de conflictos. Las teorías acerca de la agresión humana y los modelos de abordaje de los trastornos de la conducta suelen acceder a una parte sustancial del fenómeno, dejando de lado algunos elementos importantes que emergen de manera reforzante, tales como la influencia de los MASS MEDIA (medios de comunicación), las TIC (tecnologías de la información y de la comunicación), la presión de grupos sociales y las condiciones sociopolíticas adscritas a la noción de ciudadanía, identidad de grupo, sociedad y cultura; ergo los programas diseñados para evitar y reducir al máximo la violencia en cualquiera de sus manifestaciones requieren de un soporte teórico multidisciplinario cuya condición heurística instaure procedimientos y reglas metodológicas que sugieran en el quehacer psicológico una praxis cada vez mas ajustada a las condiciones biopsicosociales tanto de las victimas como de los victimarios.

Una limitación importante para la recuperación de los adolescentes con trastorno disocial es que los tratamientos de pacientes que presentan actividad delictiva, regularmente no traspasan el lugar de detención, razón por la que no presentan un patrón de seguimiento clínico una vez los adolescentes infractores se reintegran a la vida comunitaria; lo anterior dificulta el sostenimiento de la conducta funcional aprendida, por lo que a menudo las acciones reparatorias resultan paliativas al no abordar el tema central o síntoma mantenedor de la conducta criminal, misma que en muchos sentidos tiene como base las características biopsicosociales ya nombradas del trastorno disocial. Dicha dificultad conlleva un abordaje 
pobre de la amplia gama de condiciones asociadas a nivel sociofamiliar y biológico, factor que contribuye al desarrollo y mantenimiento del comportamiento violento. La intervención psicosocial debe ser ajustada a la constelación individual de cada paciente, y adscrita a los factores sociales constituyentes de la personalidad, tomando en cuenta las diversas atribuciones culturales respecto a la trasgresión y el delito, además de la búsqueda de un aumento de la comprensión multifactorial de la agresión, lo que conlleva el replanteamiento del tema de la reducción de la violencia en la sociedad, el castigo y la reparación de las consecuencias del delito. Para ello las instituciones deben valerse de acciones colectivas desde el ámbito social-comunitario, el apoyo estatal de los entes territoriales, estrategias preventivas conjuntas de los miembros familiares y un sólido anclaje a indicadores de convivencia desde los escenarios educativos, condiciones que en sí mismas estimulan el comportamiento prosocial e incrementan considerablemente el sistema de recompensas afectivas en los adolescentes y sus familias.

\section{REFERENCIAS}

Acero, AR, Escobar, FE, Castellanos, G (2007). Factores de riesgo para violencia y homicidio juvenil. Revista Colombiana de psiquiatría, 36, 78-97. Recuperado de http://www.scielo.org.co/pdf/rcp/v36n1/v36n1a07.pdf

Achenbach, TM (1991). Manual for the Child Behavior Checklist/4-18 and 1991 profile. Burlington: University of Vermont Department of Psychiatry.

American Psychiatric Association (1994). Diagnóstic and statistical manual of mental disorders (4a. ed.). Washington, DC, EE. UU.: Autor.

Anckarsater, HI (2006). Central nervous changes in social dysfunction: Autism, aggression, and psychopathy. Brain Research Bulletin, 14, 69(3), 259-65.

Anderson, CA. Bushman, BJ (2002). Human aggression. Annual Review of Psychology, 53, 27-51. Recuperado de http://www.psychology.iastate.edu/faculty/caa/abstracts/20002004/02ab.pdf

Andrade, JA, Portillo, J (2012). Asociación entre el consumo de sustancias psicoactivas y actividad delictiva en adolescentes. Revista Electrónica de Psicología Social Poiesis, 23, 1-10. Recuperado de http://www.funlam.edu.co/revistas/index.php/poiesis/article/viewFile/314/310

Atkins, R, Hart, D (2003). Neighborhoods, adults, and the development of civic identity in urban youth. Applied Developmental Science, 7, (3), 156-164.

Averasturi, Knodel, M. (Eds.). (1996). La adolescencia normal. Un enfoque psicoanalítico. Barcelona: Editorial Paidós.

Barkley, RA (1998). A theory of ADHD: Inhibition, executive functions, selfcontrol, and time. In Barkley RA, ed. Attention deficit hyperactivity disorders: a handbook for diagnosis and treatment. New York: Guilford; 1998. p. 225-62.

Barkley, RA (1990). Attention-Deficit Hyperactivity Disorder. A Handbook of Diagnosis and Teratment. New York: Guilford Press.

Barkley, RA (1997). Niños desafiantes. Materiales de evaluación y Folletos para los padres. (Traducción al español: J. J. Bauermeister y asociados). New York: Guilford Press.

Barkley, RA (1997). ADHD and the nature of self-control. New York: Guilford Press. Barkley, RA, Edwards, GH, Robin, AL (1999). Defiant Teens: A Clinician's Manual for Assessment and Family Intervention. New York; Guilford Press Publications. 
Baró, IM (1984). Acción e Ideología. Psicología social desde Centroamérica. El Salvador UCA Editores..

Blackburn, R. (2000). Classification and assessment of personality disorders in mentally disordered offenders: psychological perspective. Journal Criminal Behaviour ana Mental Health, 10( 4), 8-33.

Brook, DW, Brook, JS, Rosen, Z, De la Rosa, M, Montoya, ID, Whiteman, M (2003). Early risk factors for violence in Colombian adolescents. Journal of the American Psychiatric Association (APA), 160,1470-8.

Borduin CM. (1999). Multisystemic treatment of criminality and violence in adolescents. Department of Psychology, University of Missouri, Columbia. Journal of the American Academy of Child and Adolescent Psychiatry, 38 (3), 242-249.

Bornovalova, MA, Hicks, BM, Iacono, WG, McGue, M (2010). Familial Transmission and Heritability of Childhood Disruptive Disorders. Department of Psychology, University of Minnesota, Minneapolis. The American Journal of Psychiatry, 167, 1066-1074 . Recuperado de http://aip.psychiatryonline.org/article.aspx?articleid=102424

Brennan, W (1998). Aggression and violence: examinig the theories. Nursing Estándar. RCN publishing company, 12, 27, 36-38.

Caballo, VE, Simón, MA (2005). Manual de psicología clínica infantil y del adolescente. Madrid: Pirámide.

Campbell, A (1999). Staying alive: evolution, culture, andwomen's intrasexual aggression. Behavioral and brain sciences, 22, 203-52.

Caron, C, Rutter, M (1991). Comorbility in child psychopathology: concepts, issues, and research strategies. Journal Child Psychology and Psychiatry, 32: 1063-1080.

Charles, SC, Scheier, MF (1997). Teorías de la Personalidad (3a. ed.). México: PrenticeHall Hispanoamérica.

Corsi, J (1999). Violencia masculina en la pareja. Una aproximación al diagnóstico y a los modelos de intervención. Buenos Aires: Ediciones Paidós.

Currie, E (2000) Sociological Perspectives on Juvenile Violence. Child and Adolescent Psychiatric Clinics of North America, 9(4).

DANE (2005). Departamento Administrativo Nacional de Estadística. Informe especial censo general 2005. Bogotá: Departamento Administrativo Nacional de Estadística; 2005.

Díaz, M, Díaz-Sibaja, MA (2005). Problemas cotidianos del comportamiento infantil. En Comeche, Ma . I. y Vallejo-Pareja, M. A.: Manual de terapia de conducta en la infancia. (pp. 419-463) Madrid: Dykinson.

Dionea, G, Tremblay, R, Boivin, M, Laplante, D, Pérusse, D (2003). Physical aggression and expressive vocabulary in 19-month-old twins. Developmental Psychology, 39, (2), 261-273.

Durán, E (2006). Impacto de la participación en los grupos armados sobre la salud de los Adolescentes. En Informe Especial sobre Violencia contra la infancia en Colombia. Ministerio de la protección social. Recuperado de http://www.catedradh.unesco.unam.mx/BibliotecaV2/Documentos/Trata/Informes/in forme infancia.pdf

Erikson, E (1959). Infancia y Sociedad. Buenos Aires: Editorial Hormé.

Faraone, SV, Perlis, RH, Doyle, AE, Smoller, JW, Goralnick, JJ, Holmgren, MA, Sklar, P (2005). Molecular genetics of attention-deficit/hyperactivity disorder. Biological 
Psychiatry, 2005;57(11):1313-1323.

Farrington, DP, (1994). Human development and criminal careers. En: Maguire, M., Morgan, R. y Reiner, R. (Eds.), The Oxford Handbook of Criminology (pp. 511584). Oxford: Clarendon Press.

Farrington, DP (1995). The development of offending and antisocial behaviour from childhood: Key findings from Cambridge study in delinquent development. Journal Child Psychology and Psychiatry, 36, 929-64.

Farrington, DP (2002). Criminology. Criminal Behavior and Mental Health, 12 (4),510-516. Farrington, DP (2004). Conduct disorder, aggression, and delinquency. En Lerner, R M \& Steinberg, L. (Eds.), Handbook of Adolescent Psychology, (2a ed.)., (Pp. 627-664). Hoboken, Nueva Jersey, EE.UU.: John Wiley \& Sons Inc, xi, 852 pp.

Ferrando-Lucas, MT (2006). Trastorno por déficit de atención e hiperactividad: factores etiológicos y endofenotipos. Revista de Neurología, 42 (2), 9-11.

FIC (2006). Fogarty International Center of the U.S. National Institutes of Health, The World Bank, The World Health Organization, Population Reference Bureau, Bill \& Mellinda Gates Foundation. Adolescent health. Washington D.C.: Fogarty Internacional Center of the U.S. National Institutes of Health, The World Bank, The World Health Organization, Population Reference Bureau, Bill \& Mellinda Gates Foundation; 2006.

García, PT, Armas, V (2009). Comorbilidad, Personalidad, Estilos Educativos y Problemas de Conductas en Adolescentes. Colegio Oficial de Psicólogos de Madrid. Anuario de Psicología Jurídica, Vol. 18, 2009, pp. 21-30.

Garrido, V, López, L. (2006). El Rastro del Asesino. El Perfil Psicológico de los Criminales en la Investigación Policial. Barcelona: Editorial Ariel.

Geen, RG (1998). Aggression and antisocial behaviour. En D. Gilbert, S. Fiske y G. Lindzey, The handbook of social psychology, 3, 317-356. New York: McGraw-Hill.

Gergen, K (2006). El yo saturado. Dilemas de identidad en el mundo contemporáneo. Barcelona: Colección Surcos, Editorial Paidós.

Hart, EL, Lahey, BB, Loeber, R, Applegate, B, Frick, PJ (1995). Developmental changes in attention-deficit hyperactivity disorder in boys: A four-year longitudinal study. Journal of Abnormal Child Psychology, 23, 729-750.

Henao, J. (2005). La prevención temprana de la violencia: una revisión de programas y modalidades de intervención. Revista UniversitasPsychologica, 4, 161 - 177.

Henggeler, SW, Schoenwald, SK, Borduin, CM, Rowland, MD, Cunningham, PB (1998). Multisystemic Treatment of Antisocial Behaviorin Children and Adolescents. New York: Guilford.

Herndon, RW, Iacono, WG (2005). The familial transmission of antisocial behavior from parent to child. Psychol Med; 35:1815-1824. Recuperado de http://www.ncbi.nlm.nih.gov/pubmed/16300694

Hudziak, JJ (2003). Genética del trastorno por déficit de atención, en E. Brown y E. Thomas. Trastornos por déficit de atención y comorbilidad de niños, adolescentes y adultos. Barcelona: editorial Masson.

Jacobs, PA, Brunton, M, Melville, MM, Brittain, RP, McClemont, WF (1965). Aggressive Behaviour, Mental Sub-normality and the XYY Male. Naturaleza, 208, 1351-1352.

Khan, SA, Faraone, SV (2005) The genetics of attention-deficit/hyperactivity disorder: A literature review of 2005. Curr Psychiatry Rep, 8(5):393-397. 
Klevens, J (2000). Estrategias para la prevención temprana de la violencia en niños. Medellín: Alcaldía de Medellín, Programa de Convivencia Ciudadana, Secretaria de Educación y Cultura.

Knopik, VS, Heath, AC, Jacob, T, Slutske, WS, Bucholz, KK, Madden, PA, (2006). Maternal alcohol use disorder and offspring ADHD: disentan-gling genetic and environmental effects using a children-of-twins design. Psychol Med; 36:1461-1471 Recuperado de http://www.ncbi.nlm.nih.gov/pubmed/16734942

Kuther, TL, Wallace, SA (2003). Community violence and sociomoral development: An African American cultural perspective. American Journal of Orthopsychiatry, 73, (2), 177-189.

Lahey, BB, Piacentini, JC, McBurnett, K, Stone, P. Hartdagen, S. Hynd, G (1998). Psychopathology in the parents of children with conduct disorder and hyperactivity. Journal Am Acad Child Adolesc Psychiatry, 27,163-170. Recuperado de http://www.ncbi.nlm.nih.gov/pubmed/3360717

Litrownik, AJ, Newton, R, Hunter, WM, English, D. Everson, DM (2003). Exposure to family violence in young at risk children: A longitudinal look at the effects of victimization and witnessed physical and psychological aggression. Journal of Family Violence, 18 (1), 59-73.

Llorente, MV, Chaux, E, Salas, LM (2005). Violencia intrafamiliar y otros factores de riesgo de la violencia juvenil en Colombia. Bogotá: Departamento Nacional de Planeación, Universidad de los Andes.

Loeber, R. Hay, D (1997). Key issues in the development of aggression and violence from childhood to early adulthood. Annual Reviews in Psychology, 43, 371-410.

Luciano, C (1997). Características del comportamiento en la infancia y la adolescencia. En Luciano, C. Manual de psicología clínica. Infancia y adolescencia. $\left(2^{a}\right.$ ed.)., (Pp. 21-70). Valencia: Promolibro.

Malone, SM, Iacono, WG. McGue, M (2002). Drinks of the father: father's maximum number of drinks consumed predicts externalizing disorders, substance use, and substance use disorders in preadolescent and adolescent offspring. Alcoholism 2002; 26,1823-1832. Recuperado de http://www.ncbi.nlm.nih.gov/pubmed/12500106

Margolin, G, Gordis, EB (2000). The effects of family and community violence on children. Annual Review of Psychology, 51, 445-479.

Marina, JA, \& López, M. (1999). Diccionario de los sentimientos. Barcelona: Editorial Anagrama.

Marmorstein, NR, Iacono, WG. McGue, M (2009). Alcohol and illicit drug dependence among parents: associations with offspring externalizing disorders. Psychol Med, 39, 149-155.

Martínez, M, Henao, GC, Gómez, LA (2009). Comorbilidad del trastorno por déficit de atención e hiperactividad con los trastornos específicos del aprendizaje. Revista Colombiana de Psiquiatría, 38, 178-194. Asociación Colombiana de Psiquiatría Bogotá, Colombia. Recuperado de http://www.scielo.org.co/scielo.php?pid=S0034$\underline{74502009000500011 \& \text { script=sci arttext }}$

Mash, EJ, Graham, SA (2001). Clasificación y tratamiento de la psicopatología infantil. En Caballo, V. E. y Simón M. A. (Dirs.) Manual de psicología clínica infantil y del adolescente. Trastornos generales. Madrid: Pirámide.

Maturana, H. (1995). La Democracia es una Obra de Arte. Colombia: Editorial Magisterio. 
Meloy, J. Hempel, A. Mohandie, K. Shiva, A. Gray, B. (2001). Offender and offence characteristics of nonrandom sample of adolescent mass murders. J Am Acad Child Adolesc Psychiatry. 40(6):719-28.

Méndez, F. Espada, J. Orgilés, M. (2006). Intervención con niños y adolescentes. En Méndez, F. X., Espada, J. P. y Orgilés, M. (Coords.). Intervención psicológica y educativa con niños y adolescentes. Estudio de casos escolares. (pp. 21-49) Madrid: Pirámide.

Rojas, AM, Malpica, CR (2006). Aproximación al adolescente con trastorno de conducta Disocial. Investigación en Salud, Universidad de Guadalajara, México: 8(2), 121128.

Monroy, A (1995). Pubertad, adolescencia y cultura juvenil. En: Organización Panamericana de la Salud. La salud del adolescente y del joven. Washington, D.C.: OPS; 1995, 2735 .

Moreno, I (2002). Terapia de conducta en la infancia. Guía de intervención. Madrid: Pirámide.

Moreno, I (2005). Características de la intervención terapéutica en la infancia. En Comeche, $\mathrm{M}^{\mathrm{a}}$. I. y Vallejo-Pareja, M. A. Manual de terapia de conducta en la infancia. (Pp. 25-68). Madrid: editorial Dykinson.

MPS. (2004). Ministerio de la Protección Social de Colombia. Estudio de salud mental, Colombia, 2003. Bogotá: Ministerio de la Protección Social.

MPS. (2004). Encuesta nacional sobre consumo de sustancias psicoactivas en jóvenes escolares de 12 a 17 años. Bogotá: Ministerio de la Protección Social; 2004.

MPS. (2010). Ministerio de la Protección Social de Colombia. Situación de la salud mental del adolescente. Estudio nacional de salud mental Colombia.

Muñoz, JJ (2004). Factores de riesgo y protección de la conducta antisocial en adolescentes. Revista de psiquiatría, 31(1):21-37. Recuperado de http://www.nexusediciones.com/pdf/psiqui2004 1/ps-31-1-004.pdf

Olweus, D. Mattsson, A. Schalling, D. Low, H (1980) Testosterone, aggression, physical and personality dimensions in normal adolescent males. Journal Psychosom Med, 42:253-69.

OMS (2005). World Health Organization. WHO Atlas Child and Adolescent. Ginebra: World Health Organization; 2005.

Orjales, V (2003). Déficit de atención con hiperactividad. Manual para padres y educadores. Madrid: editorial Cepe.

Palacio, V (2011). La delincuencia juvenil: un reto para descifrar una metáfora relacional.
Colombia:
Revista
Eleuthera,
5,15-35.
Recuperado
de http://eleuthera.ucaldas.edu.co/downloads/Eleuthera5 4.pdf

Patterson, GR, Reid, J, Dishion, T (1992). Antisocial Boys. Eugene, OR: Castalia

Perea, C (2007). OEA, Secretaria General de la Organización de los Estados Americanos. Departamento de seguridad pública definición y categorización de pandillas. Anexo II informe Colombia. Recuperado de http://www.oas.org/dsp/documentos/pandillas/AnexoII.Colombia.pdf

Piaget, J (1969). Biología y conocimiento. México: Editorial Siglo XXI.

Pineda, DA, Puerta, I (2001). Prevalencia del trastorno disocial de la conducta en adolescentes, usando un cuestionario de diagnóstico epidemiológico. Revista de Neurología. 32 (7)

Pineda, DA, Puerta, I (2001a). Cuestionario de auto informe para el diagnóstico de 
Trastorno Disocial de la Conducta en adolescentes escolarizados. Revista de Neuropsicología, Neuropsiquiatría y Neurociencias.

Portugal, F, Araúxo, V (2004). El modelo de Russell Barkley. Un modelo etiológico para comprender los trastornos de conducta. Revista de Psiquiatría y Psicología del Niño $y$ del Adolescente, 4(1), 54-64. Recuperado de http://www.paidopsiquiatria.com/rev/numero4/art6.pdf

Raine, A, Lenz, T, Bihrle, S, LaCasse, L, Colletti, P (2000). Reduced prefrontal gray matter volume and reduced autonomic activity in antisocial personality disorder. Genetic Psychiatry, 57, 119-127.

Redondo, S, Sánchez-Meca, J, Garrido, V (1999). Tratamiento de los delincuentes y reincidencia: Una evaluación de la efectividad de los programas aplicados en Europa. Anuario de Psicología Jurídica, 11-37.

Rey, C (2001). Empatía en Niños y Adolescentes con Trastorno Disocial, y el Grado de Rechazo, Marginación Afectiva y Permisividad de que son objeto por parte de sus padres y madres. Avances en psicología clínica latinoamericana, 19, 25-36.

Rhee, SH, Waldman, ID (2002). Genetic and environmental influences on antisocial behaviour: a metaanalysis of twin and adoption studies. Psychol Bull 2002, 128: 490529.

Robins, LN (1966). Deviant children grown up: A sociological and psychiatric Study of sociopathic personality. Baltimore: William y Wilkins. (Reprinted: Huntington, NY: Krieger, 1974.351p.

Robins, LN (1981). Epidemiological approaches to natural history research: Antisocial disorder in children. Journal of the American Academy of Child Psychiatry, 20, 556680.

Rodriguez, M (2008). La delincuencia juvenil. Nuevas perspectivas criminológicas. Policía nacional de Colombia. Revista criminalidad. DIJIN. Recuperado de http://oasportal.policia.gov.co/portal/page/portal/UNIDADES_POLICIALES/Direcci ones tipo Operativas/Direccion de Investigacion Criminal/Documentacion/REVIS TA\%202007/La\%20Delincuencia\%20Juvenil.pdf

Rosario, M, Salzinger, S, Feldman, RS, Ng-Mak, DS (2003). Community violence exposure and delinquent behaviors among youth: the moderating role of coping. Journal of Community Psychology, 31, (5), 489-512.

Rutter, M, Giller, H, Hagell, A (2000). La conducta antisocial de los jóvenes. Madrid: Cambridge University Press.

Rutter, M. Guiller, H. (1988). Delincuencia juvenil. Barcelona: Martínez Roca.

Sanabria, AM, Uribe, AF (2007). Prevalencia de la delincuencia juvenil en Santiago de Cali.

Revista pensamiento psicológico, 3(009), 111-112. Recuperado de http://redalyc.uaemex.mx/pdf/801/80103909.pdf

Sánchez, AE (2000). Responsabilidad, ley, salud mental. Reflexiones en torno al nuevo Código Penal. Revista de la Asociación Española de Neuropsiquiatría, 20 (73), 109126.

Scarpa A, Raine A. (2000). Violence associated with anger and impulsivity. In The Neuropsychology of Emotion, ed. J Borod, pp. 320-39. New York: Oxford Univ. Press.

Schwartz, D, Proctor, LJ (2000). Community violence exposure and children's social adjustment in the school peer group: the mediating roles of emotion regulation and social cognition. Journal of Consulting and Clinical Psychology, 68, 670-683. 
Simon, LJ (1998). Does criminal offender treatment work? Appl. Prev. Psychol. 7:137-59

Spoont, M (1992). Modulatory role of serotonina in neural information processing: Implications for human psycho-pathology. Psychol Bull, 11,330-350

Steinhausen, HC (2003). Prevalencia de los trastornos afectivos en los niños y adolescentes: resultados de los estudios epidemiológicos en Zúrich. Acta Psychiatric Scand Suppl , 418, 20-33.

Tannock R (1998). Attention deficit hyperactivity disorder: advances in cognitive, neurobiological, and genetic research. Journal Child Psychol Psychiatry,39, 65-69.

Taylor, E. Chadwick, O, Heptinstall, E, Canckaerts, M (1996). Hyperactiviy and Conduct Problems as Risk Factors for Adolescent Development. Journal Am Acad of Chila Adolesc Psychiatry, 35(9), 1213-1226.

Tellegen, A (1993). Folk concepts and psychological concepts of personality and personality disorder. Psychological Inquiry, 4, 122-130.

Torrente, C, Kanayet, F (2005). Contribución de las competencias ciudadanas al rompimiento del ciclo de la violencia en Colombia. Un estudio a nivel nacional con niños, niñas y jóvenes de quinto y noveno grado Trabajo de grado. Universidad de los Andes Facultad de Ciencias Sociales - Departamento de Psicología.

Tremblay, RE, Schaal, B, Boulerice, B. Arseneault, L, Soussignan, R, Pérusse, D (1997). Male physical aggression, social dominance and testosterone levels at puberty: A developmental perspective. In A. Raine, D. P. Farrington, P. Brennan, \& S. A. Mednick (Eds.), Biosocial bases of violence (pp.271-291). New York: Plenum Press.

Valdez, JL, Díaz, L. Pérez, B (2005). Los hombres y las mujeres en México: Dos mundos distantes y complementarios. México: Universidad Autónoma del Estado de México.

Walzer, S, Bashir, A, Silbert, A (1990). Los factores cognitivos y conductuales en los trastornos del aprendizaje de los 47, XXY y 47, los niños XYY. Defectos de Nacimiento Orig Ser Ártico. 26. (4): 45-58

Wiggins, JS, Pincus, AL (1989). Conceptions of personality disorders and dimensions of personality. Psychological Assessment: A journal of Consulting and Clinical Psychology, 1, 305-316.

Witkin, HA, Goodenough, DR (1977). Field dependence and interpersonal behavior. Psychological Bulletin, 84, 661-689.

Zambrano, A, Pérez, L (2004). Construcción de identidad en Jóvenes infractores de Ley, una mirada desde la psicología cultural. En: Revista de Psicología de la Universidad de Chile, 13(1), 115-132.

Zuleta, E (1980). Entrevista a Estanislao Zuleta: La Educación: Un Campo de Combate. Santiago de Cali.

Zuleta, E (1992). Colombia violencia, democracia y Derechos Humanos. Bogotá Colombia: Editorial: Hombre Nuevo Editores. 
(c) (i)

Este texto está protegido por una licencia Creative Commons $\underline{4.0}$.

Usted es libre para Compartir - copiar y redistribuir el material en cualquier medio o formato- y Adaptar el documento - remezclar, transformar y crear a partir del material - para cualquier propósito, incluso comercialmente, siempre que cumpla la condición de:

Atribución: Usted debe reconocer el crédito de una obra de manera adecuada, proporcionar un enlace a la licencia, e indicar si se han realizado cambios. Puede hacerlo en cualquier forma razonable, pero no de forma tal que sugiera que tiene el apoyo del licenciante o lo recibe por el uso que hace. 